\title{
El urbanismo de Santiago de Compostela: un plano con las plazuelas de San Martín y de San Miguel, de 1709
}

\author{
Miguel TAÍn GuZMÁN *
}

\begin{abstract}
RESUMEN ABSTRACT
El presente artículo está dedicado al estudio de un plano inédito de 1709 donde se representan las plazuelas de

San Martín y de San Miguel, en el barrio intramuros de la Puerta de la

Peña de Santiago de Compostela.

Gracias al referido dibujo, analizo al detalle el entramado urbano de ambos espacios públicos y los edificios que los delimitan, particularmente la iglesia de

San Martín Pinario, el desaparecido Palacio del Tribunal de la Santa

The article focuses on the study of a 1709 inpublished street plan of two squares - San Martín and San Miguel - in the Puerta de la Peña quarter (Santiago de Compostela). This old drawing shows the urban framework of both public spaces and also the buildings around: San Martín Pinario, the lost Palacio del Tribunal de la Santa Inquisición and the paroquial church of San Miguel de los Agros.
\end{abstract} Inquisición y la iglesia parroquial de San Miguel dos Agros.

En un tomo de Actas Consistoriales de la ciudad de Santiago del año 1709 se encuentra inserto un plano de las plazuelas de San Martín y de San Miguel ${ }^{1}$ (figs. 1-4). En él, ambos espacios públicos aparecen delimitados por las plantas de los edificios que los rodean, indicándose el tipo de construcción de que se trata y, para las casas, su inquilino. También se señalan los viales que allí desembocan y sus nombres.

\footnotetext{
* Departamento de Historia del Arte. Universidad de Santiago de Compostela.

1 Archivo Histórico de la Universidad de Santiago (A.H.U.S.), Sección Ayuntamiento de Santiago, Actas Consistoriales, 1709 (mayo-octubre), fol. 512 bis.
} 
El dibujo acompaña una carta de los monjes benedictinos dirigida al ayuntamiento -es leída en el consistorio del 21 de marzo de $1709^{2}$ - en la que piden reformar el sistema de traída de agua al monasterio pues acaban de construir "una fuente con su chafariz espaciosso" en uno de los claustros, posiblemente en el Claustro de las Oficinas, y "se a reconocido serle precisso hazer una nueua arqueta». El documento no señala la autoría del plano, pero sí que se envío a «los Maestros del Monasterio... con la planta" para que informen "de la graçia que se pretende". Su autor debe de ser un artífice al servicio del monasterio de San Martín Pinario interesado en defender los derechos de los monjes al agua: probablemente se trate de Fray Gabriel de Casas.

El descubrimiento del plano es importante porque permite el estudio de las dos plazas aludidas, fruto de la evolución del entramado urbano desde la fundación de la urbe en el siglo IX, antes de las transformaciones que van a sufrir según avance el siglo XVIII y a lo largo de los siglos XIX y XX ${ }^{3}$.

\section{LA PLAZUELA DE SAN MARTÍN}

Según el plano, la plaza de San Martín está concebida en función de dos edificios monumentales, la iglesia del monasterio benedictino que le da su nombre al Oeste y el Palacio del Tribunal de la Inquisición al Norte (fig. 2). Los frentes Este y Sur se cierran con manzanas de viviendas de particulares. El perímetro cuadrangular de dicho espacio público es prácticamente el mismo que el de la plaza actual (figs. 5-6), desembocando a él las mismas calles: por el Norte la Calle de la Puerta de la Peña que conserva el nombre 4; por el Sur la Calle de la Fuente de San Miguel y la Calle da Moeda Vella que en el documento aparecen sin nombre; y por el Este la Plazuela de San Miguel. El acceso a la plaza desde los viales de los ángulos provocaba y aún provoca en el viajero que viene por primera vez a Compostela el efecto barroco de la sorpresa visual ante la belleza de los lienzos del compartimento estanco allí dispuesto. Incluso la cuesta de la plazuela de San Miguel se convierte en

\footnotetext{
2 A.H.U.S., Sección Ayuntamiento de Santiago, Actas Consistoriales, 1709 (enero-abril), fol. 208 r.v.

3 Sobre la génesis del barrio donde se ubican ambas plazuelas véase LóPEZ ALSINA, F., $L a$ ciudad de Santiago de Compostela en la Alta Edad Media, Santiago, 1988.

4 Según los hermanos FERNÁNDEZ DE BOÁN (General descripción del Reino de Galicia, mss. de hc. 1640 . He consultado una copia manuscrita del siglo XIX propiedad de X.R. Barreiro Fernández, pág. 229) «esta puerta antiguamente se llamaba De los Agros por estar cerca de ella, á la parte de dentro, acima de la fuente, San Miguel de los Agros, parroquia antiquisima. Y después se le troco el nombre conservando el que hoy tiene por estar por aquella parte muchas peñas".
} 
El urbanismo de Santiago de Compostela: un plano con las plazuelas de San Martín...

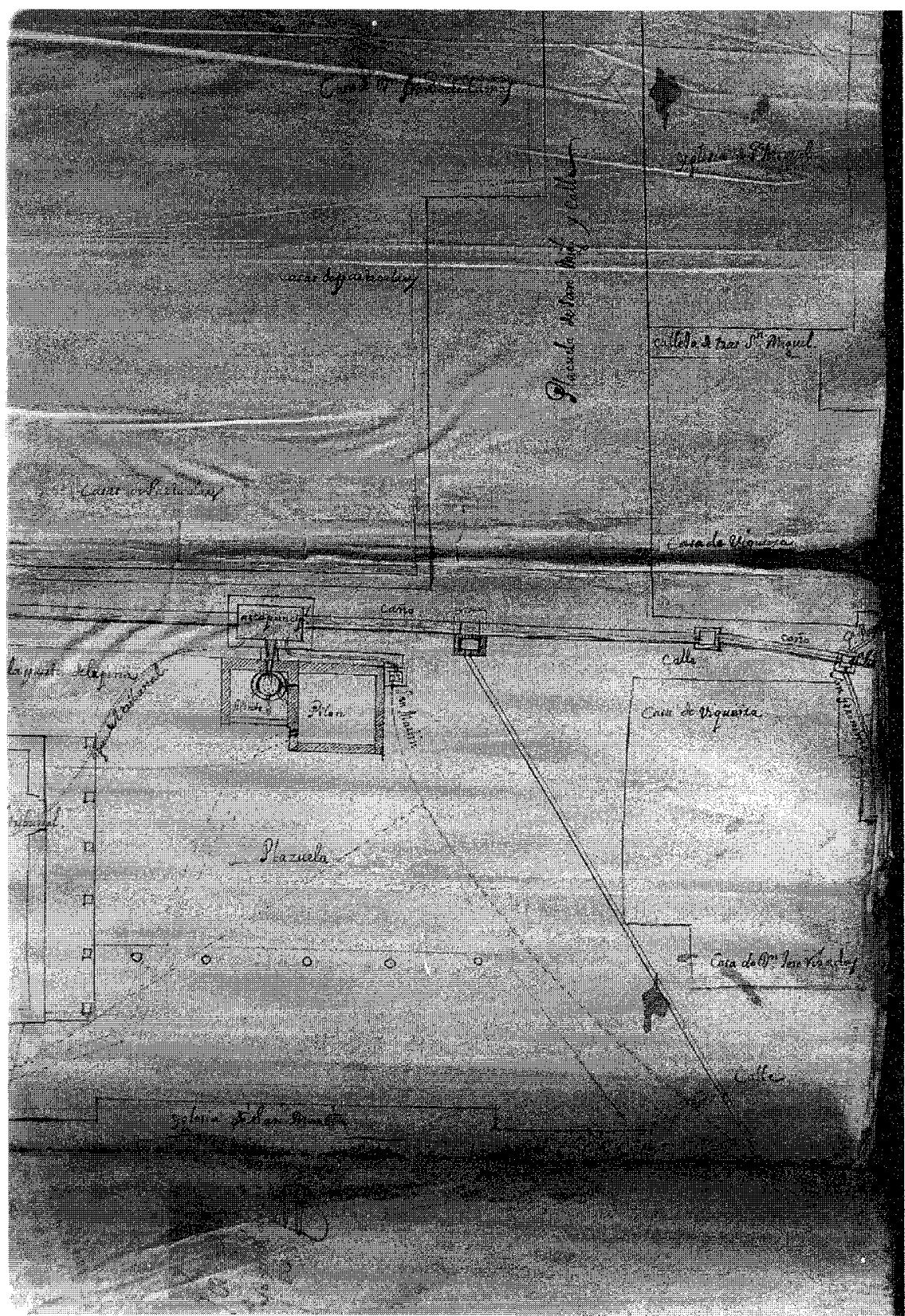

Fig. 1. Plano de las plazuelas de San Martín y de San Miguel (c. 1705). 


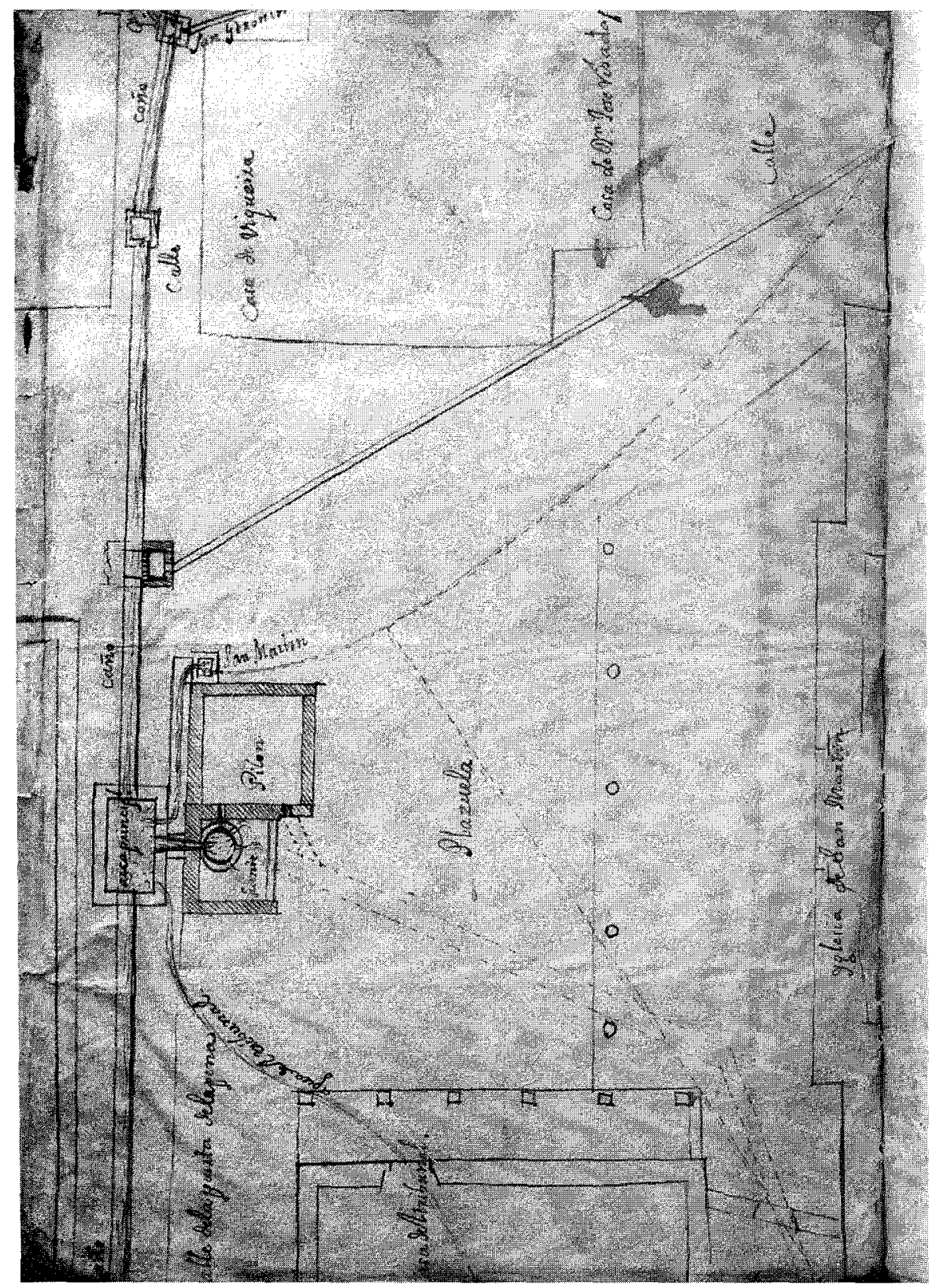

Fig. 2. Detalle del plano anterior. La Plazuela de San Martín. 


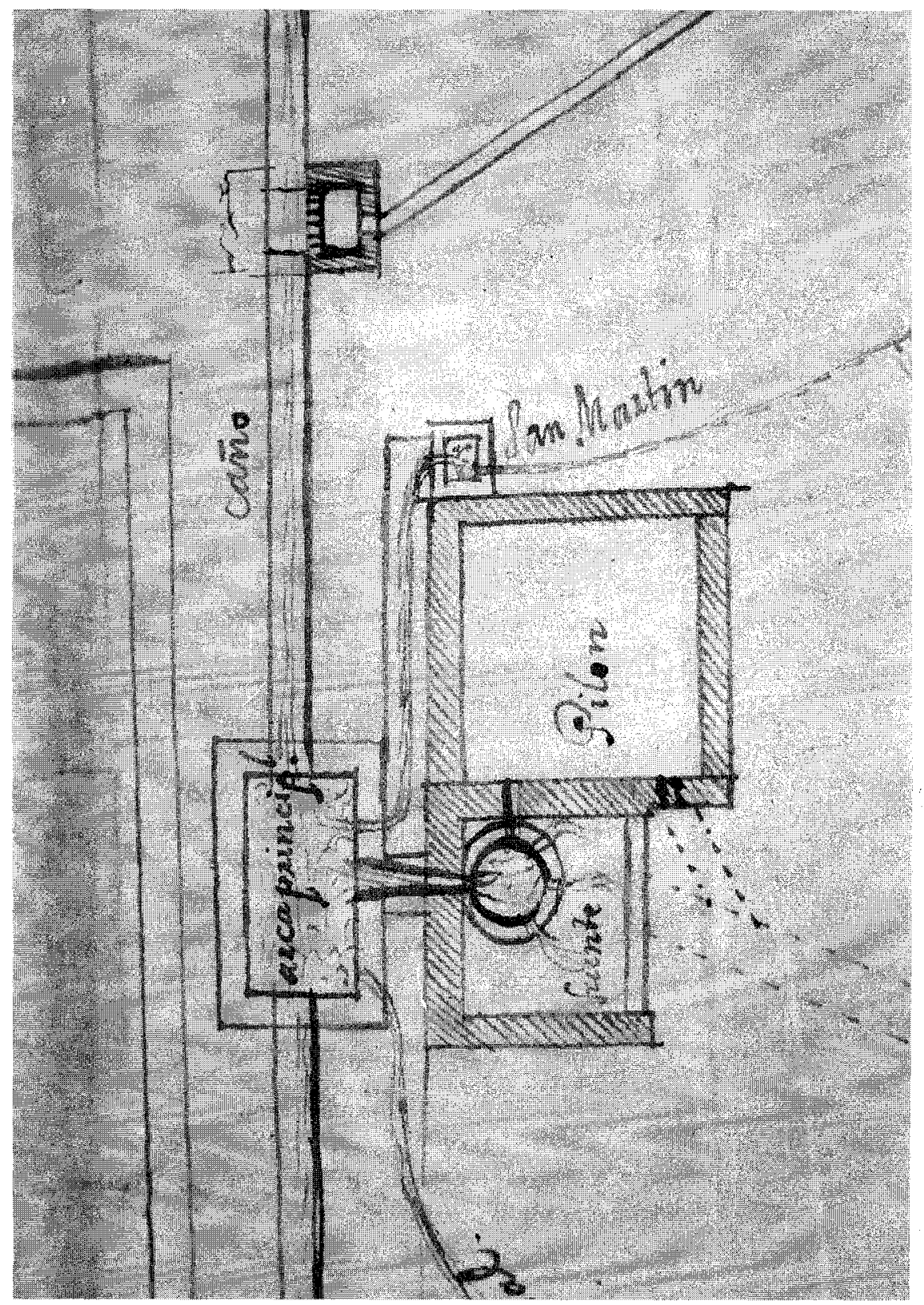

Fig. 3. Detalle del plano. La Fuente de San Miguel. 


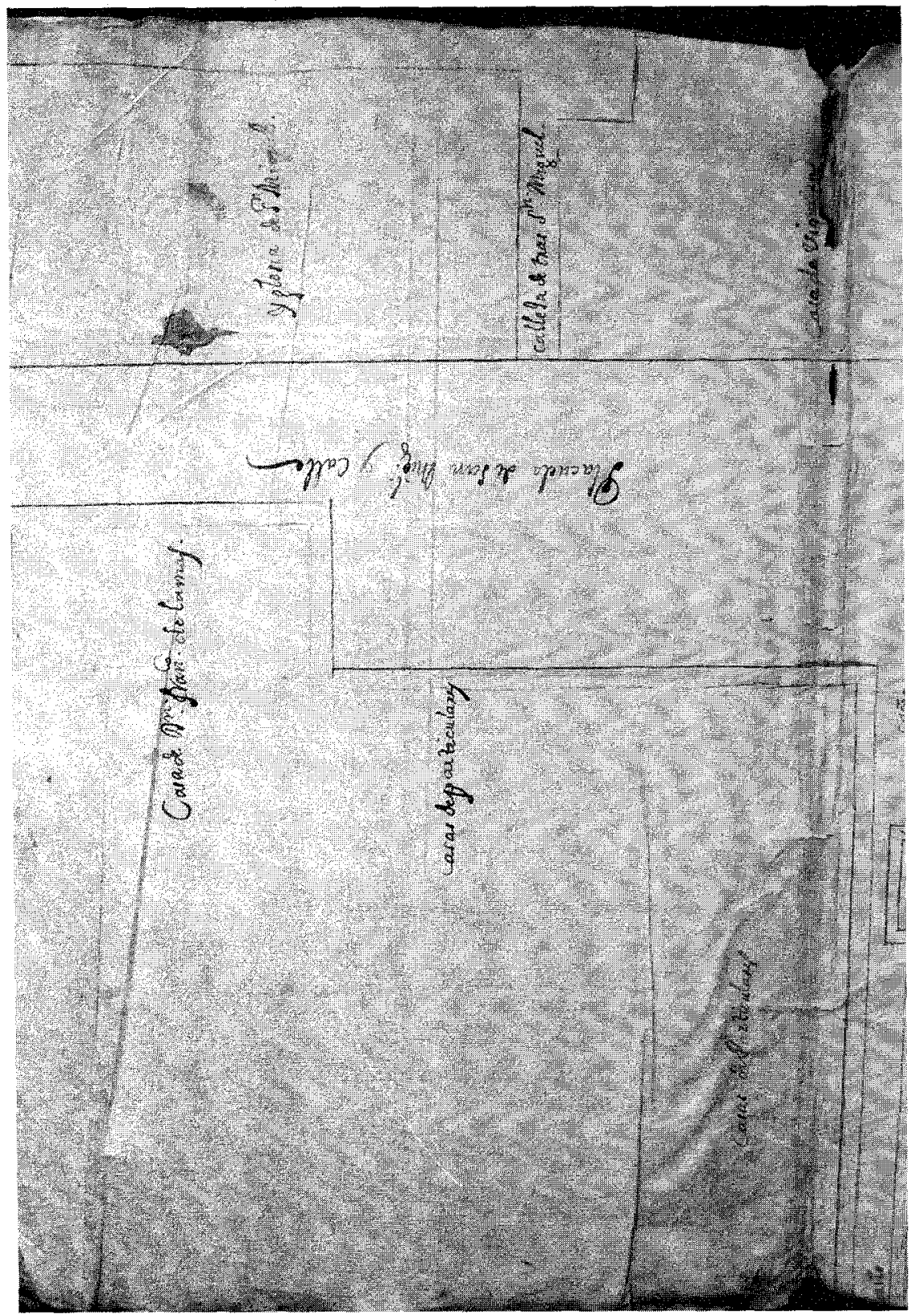

Fig. 4. Detalle del plano. La Plazuela de San Miguel. 
El urbanismo de Santiago de Compostela: un plano con las plazuelas de San Martín...

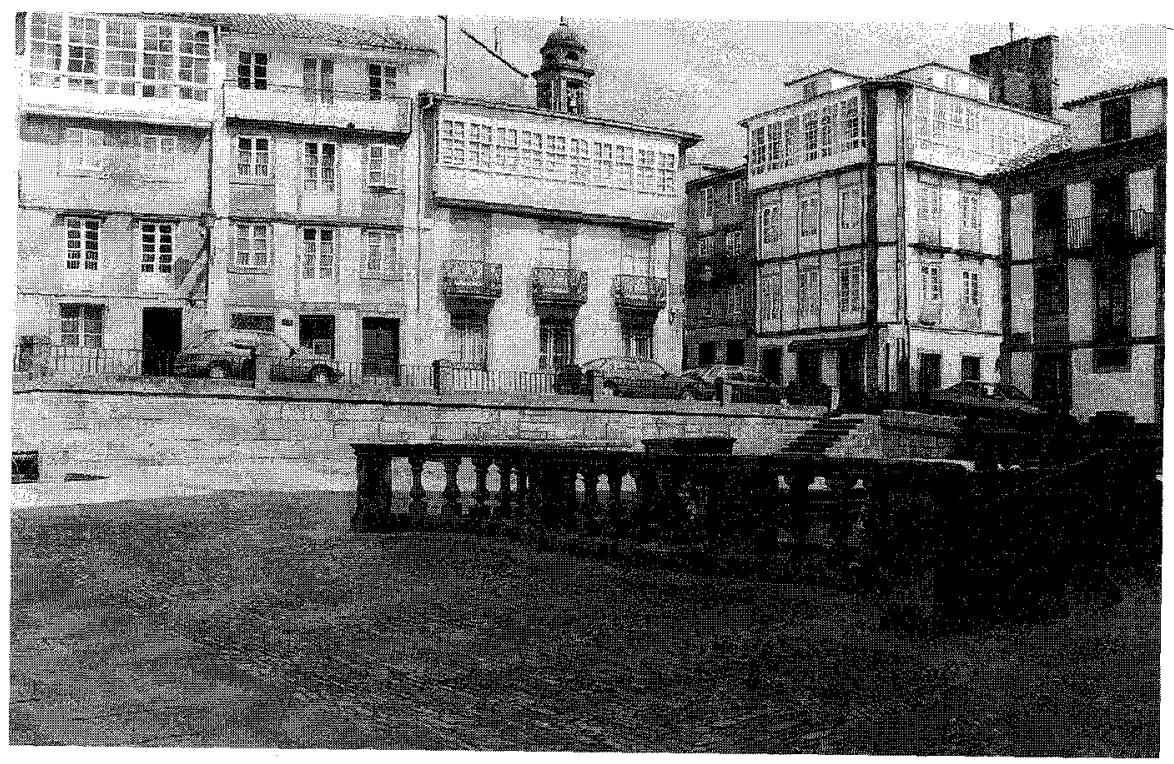

Fig. 5. La Plazuela de San Martín hoy.

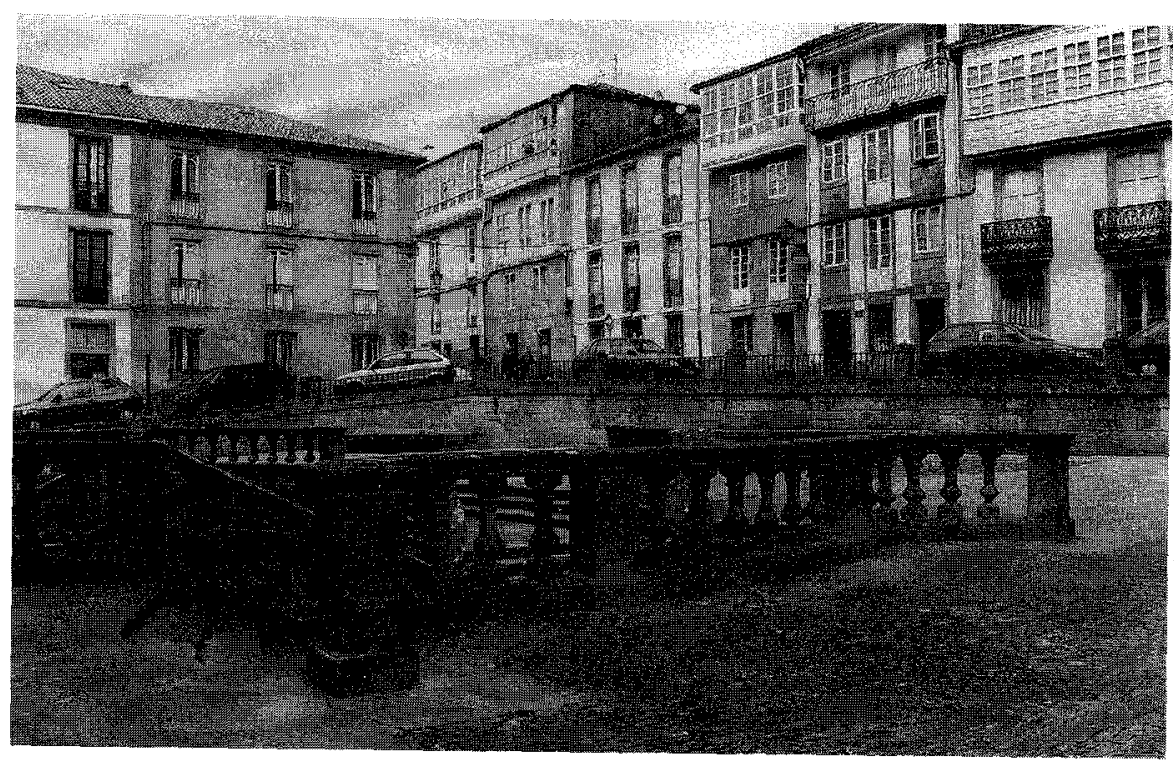

Fig. 6. La Plazuela de San Martín. 
un aliado del tracista de la fachada de la iglesia de San Martín. Su larga perspectiva tiene su recompensa al fondo como punto de atracción ${ }^{5}$. Y todo ello pese a que en nuestro siglo Pons Sorolla suprimió la suave pendiente de la plaza de San Martín ${ }^{\circ}$, partiéndola en sus actuales distintos planos ${ }^{7}$.

De la iglesia monacal, únicamente figura dibujada la planta de la fachada, obra de Mateo López, que la construyó a partir de $1597^{8}$ (fig. 7). Aunque la plazuela ya existía incluso antes de asentarse allí la Inquisición, a Mateo López puede deberse también parte de su trazado. Él debió despejarla de anteriores construcciones para que se pudiese contemplar en todo su esplendor el retablo pétreo de la portada ${ }^{9}$. Es más, la subordinación de la nueva iglesia a la plaza se demuestra en el hecho de que el arquitecto de origen portugués no duda en sacrificar la orientación canónica del templo, habilitando la entrada al mismo al Este y la capilla mayor en el lado contrario ${ }^{10}$. Si se hubiesen construido las dos torres proyectadas en la fachada, la plaza habría ganado más monumentalidad y su integración en la trama urbana habría sido aún mayor.

Es una lástima que no aparezca en el plano la escalinata interior de acceso al templo calificada por Mendoza de los Ríos en 1731 de "admirable»".

\footnotetext{
5 Sobre el tema de las perspectivas en Santiago véase MARTín GonZÁlEZ, J.J., «Perspectivas barrocas de Santiago de Compostela", Goya, 1964, 28-34.

- Viejas fotografías dan testimonio del aspecto de la plaza antes de la remodelación.

Cfr. Bonet CORREA, A., «La estructura urbana de Santiago de Compostela», Proyecto y ciudad histórica, $1^{2}$ Seminario Internacional de Arquitectura en Compostela, 1976, 33.

- Según JeRÓNImo del Hoyo (Memorias del arzobispado de Santiago, Mss. de 1607 conservado en el Archivo Histórico Diocesano de Santiago. El texto que he utilizado es una transcripción del manuscrito original publicada por Rodriguez GonzÁlez, A., y VARELA JÁCOME, B., Santiago, $1952,64)$ en 1607 se «tiene acabada la portada". Sobre la iglesia actual véanse PÉrEZ COSTANTI, P., Diccionario de artistas que fiorecieron en Galicia durante los siglos XVI y XVII, Santiago, 1930, 335-336; BONEr CORREA, A., La arquitectura en Galicia durante el siglo XVII, Madrid, 1984 ( $1^{\mathrm{a}} \mathrm{ed}$. de 1965), 105-109; FERNÁNDEZ REY, A.A., "Varios séculos de actividade constructiva en San Martiño Pinario», Galicia no Tempo, Santiago, 1991, 351-393; VILA JATO, M'.D., "San Martiño Pinario no seu acontecer pasado: o esplendor dun mosteiro", Galicia no Tempo, Santiago, 1991, 69-79; Vigo Trasancos, A., "La iglesia monástica de San Martín Pinario en Santiago de Compostela. Proyecto, fábrica y artífices", Compostellanum, 1993, 337-361; IDEM, "Sobre el arquitecto portugués Mateo López, la iglesia monástica de San Martín Pinario y el clasicismo en Compostela (1590-1605)", Actas del X Congreso del C.E.H.A., Madrid, 1994, 327-335; Gor DIz, A., "Mateo López y su interpretación de los modelos clasicistas", Actas del X Congreso del C.E.H.A., Madrid, 1994, 317-326.

9 Sobre la lectura iconográfica de la portada véase RoSENDE VALDÉS, A.A., «El Renacimiento», Historia del Arte Gallego, Madrid, 1982, 225-226.

to Idea ya expuesta en su día por VIGo Trasancos, A., "Cidade e Urbanismo na Galicia do Antigo Réxime. Do Renacemento á llustración», Galicia no Tempo, Santiago, 1991, 156; IDEM, La iglesta monástica de San Martín Pinario..., art. cit., 338.

1 Cfr. MENDOZA DE LOS RIOS, P., Theatro moral, $y$ politico de la noble academia compostelana, Santiago, 1731: 83.
} 


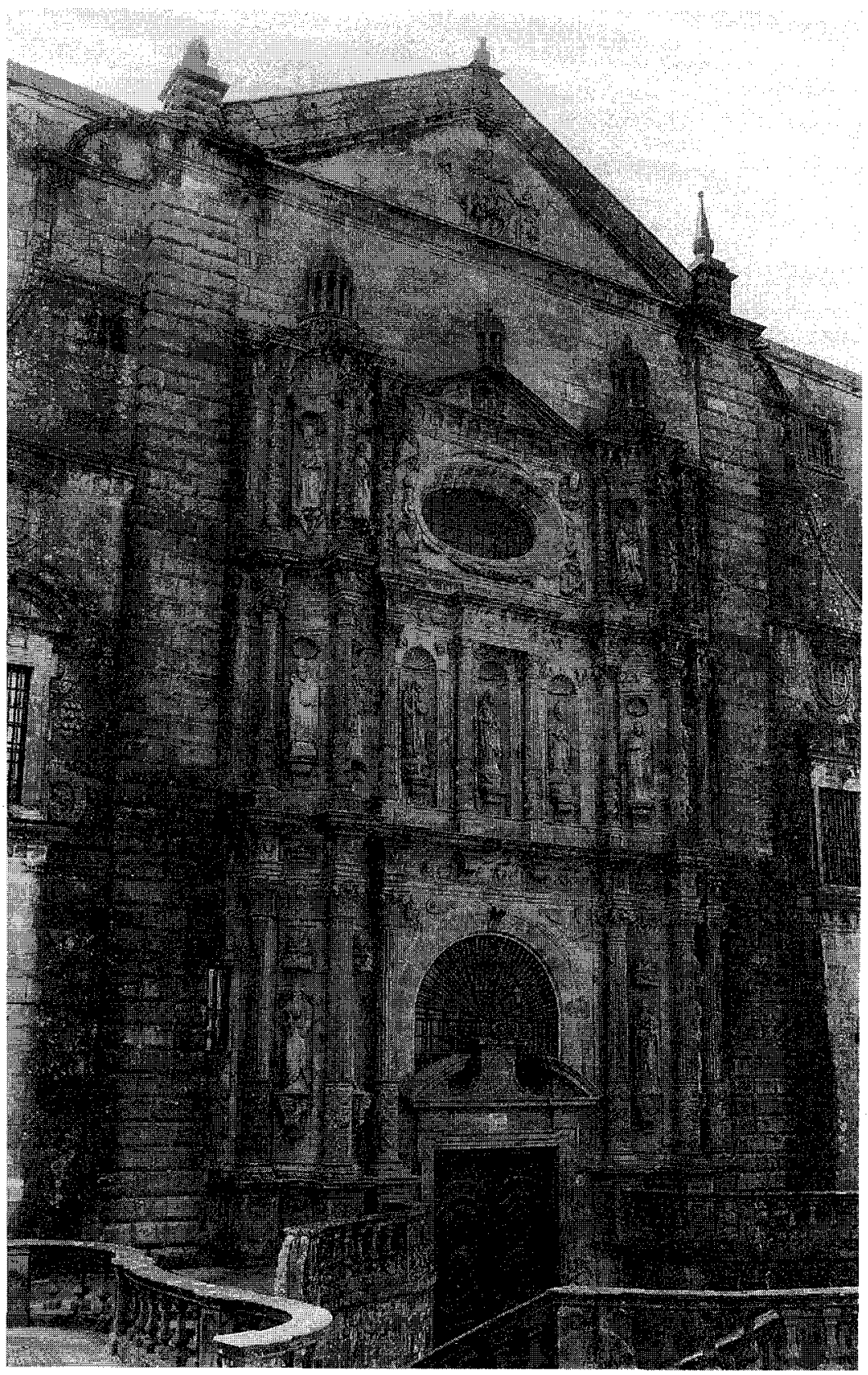

Fig. 7. La fachada de la Iglesia de San Martín Pinario. 
Hoy se carece de todo testimonio gráfico de ella. Fue destruida avanzado el siglo XVIII, en torno a 1770 y 1773 , en el momento en que se construyen las actuales escaleras exteriores barrocas, siguiéndose, al parecer, trazas de Fray Manuel de los Mártires. La nueva obra obligó a excavar delante de la fachada, resultando excesivamente alta la puerta anterior de Mateo López, en arco de medio punto, lo que hizo necesario hacer otra nueva convirtiendo la primitiva en claraboya (fig. 7).

Enfrente de la iglesia aparece dibujado un espacio trapezoidal que sugiere la idea de un terreno en pendiente, acaso incluido en la propiedad del monasterio. Así parece indicarlo la planta circular de cinco pilotes o postes, como los actuales del Hospital Real ${ }^{12}$ y los que cierran la lonja a la que da la principal fachada del propio monasterio de San Martín, y que también tuvieron, según consta, el Colegio de San Jerónimo ${ }^{13}$ y el Colegio de Fonseca ${ }^{14}$.

Del Palacio del Tribunal de la Santa Inquisición sólo aparece dibujada la planta de la fachada, también con pilotes de sección cuadrada delante de ella, delimitando su jurisdicción. Desde 1575 el Santo Tribunal se estableció en esta plaza, en las casas del Conde de Monterrey, que sufrieron múltiples reformas para adaptarse a su nueva función (fig. 8). La más importante fue debida a Diego de Romay que entre 1677 y 1681 construyó prácticamente una sede nueva ${ }^{15}$. Un alzado de Fernando de Casas del año 1727 podría ser la fachada del edificio del plano ${ }^{16}$ (fig. 9). El que en este último dibujo aparezca la entrada del edificio en su eje y no

\footnotetext{
12 Las cadenas son un añadido reciente.

3 Véanse los planos de la Plaza del Obradoiro publicados por BONET CORREA (La arquitectura..., op. cit., lám. 216) y Pérez Rodríguez («Un escenario privilegiado para las fiestas del Apóstol Santiago: la Plaza del Obradoiro", Cuadernos de Estudios Gallegos, 1995, 255).

${ }^{14}$ Cfr. PÉrez Costanti, P., op. cit., 250. Algún autor a la hora de analizar planos antiguos de la ciudad confunde la planta de los postes de los edificios enumerados con soportales (cfr. ORTEGA ROMERO, M." DEL S., "Aspectos urbanísticos del barroco compostelano: voladizos y soportales", Revista de la Universidad Complutense, $1973,1^{\circ}$ semestre, 177).

15 Archivo Histórico Nacional, Sección Inquisición, leg. 4.557-3, fols. 26v., 28r., 53v.-54r. y 57r.v. Sobre el tema véanse Bonet CorREA, A., op. cit., 439-442; OrTEGa Romero, M. ${ }^{a}$ DEL S., "Un proyecto de Fernando de Casas para el Tribunal de la Inquisición de Santiago", Jubilatio II: Homenaje de la Facultad de Geografía e Historia a los profesores don Manuel Lucas Alvarez y don Angel Rodríguez, Santiago, 1987, 653-668.

16 FERNANDO DE CASAS acompaña el dibujo del alzado del edificio con otro alzado, que es su proyecto para un nuevo frente. También se conserva el dibujo de la planta del edificio hecha por el mismo autor con una ampliación que entonces se pretendía hacer. Todos los dibujos -junto con otros de nuevas propuestas- están en el A.H.U.S. y han sido publicados por ORTEGA Romero (Un proyecto..., art. cit., 666-668) y García IgLESIAS (Fernando de Casas Novoa, Santiago, 1993, 56-58). BONET CORREA (op. cit., lám. 230) ha publicado los alzados atribuyéndoselos al propio Diego de Romay. CONTRERAS (El Santo Oficio de la Inquisición de Galicia, Madrid, 1982, 354-355) ha publicado otra planta del Santo Tribunal, pero sin dar ningún dato sobre su autoría, cronología o contexto.
} 


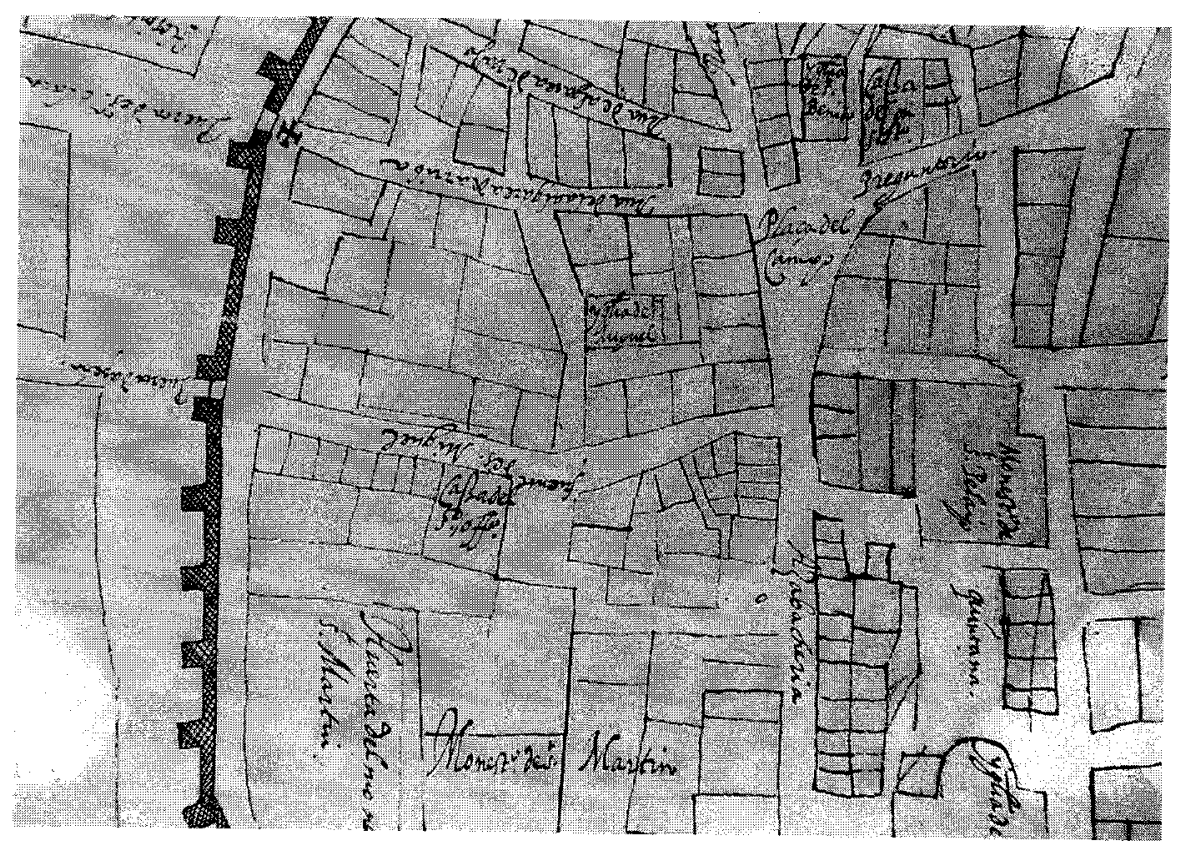

Fig. 8. Detalle de un plano de la ciudad de Santiago de 1595. Las plazuelas de San Martín $y$ de San Miguel.

en un lateral, como se ve en el plano en estudio, puede deberse a un cambio posterior.

Recién hechos los nuevos planos por Fernando de Casas, el Santo Oficio trasladó su sede extramuros, a la Puerta de la Mamoa: en un plano de hacia 1750, atribuido a Francisco Ferreiro, el solar ya está libre (fig. $10)$. Dicho solar será ocupado en el futuro por una manzana de casas tal y como se nos presenta hoy en día.

Descentrada de la plaza se dispone la Fuente de San Miguel ${ }^{17}$ (fig. 3), cuyo mantenimiento corría a cargo del Ayuntamiento y del fontanero municipal. Ella, junto con la de la Plaza del Campo - hoy Plaza de Cervantes- y la de las Platerías, figuran entre las principales proveedores de agua a los habitantes de la ciudad. $Y$ es que la plaza era atra-

17 En 1542 los vecinos la califican como la fuente principal de la ciudad (cfr. RoDriguez ÁNGEL, A., "La ciudad de Santiago en 1542», Cuadernos de Estudios Gallegos, 1970, 277). En 1726 Guillermo Manier afirma que no es más «bella» que la de la Plaza del Campo (ctr. García MErCAdAL, J., Viajes de extranjeros por España y Portugal, t. III, Madrid, 1962, 363). 


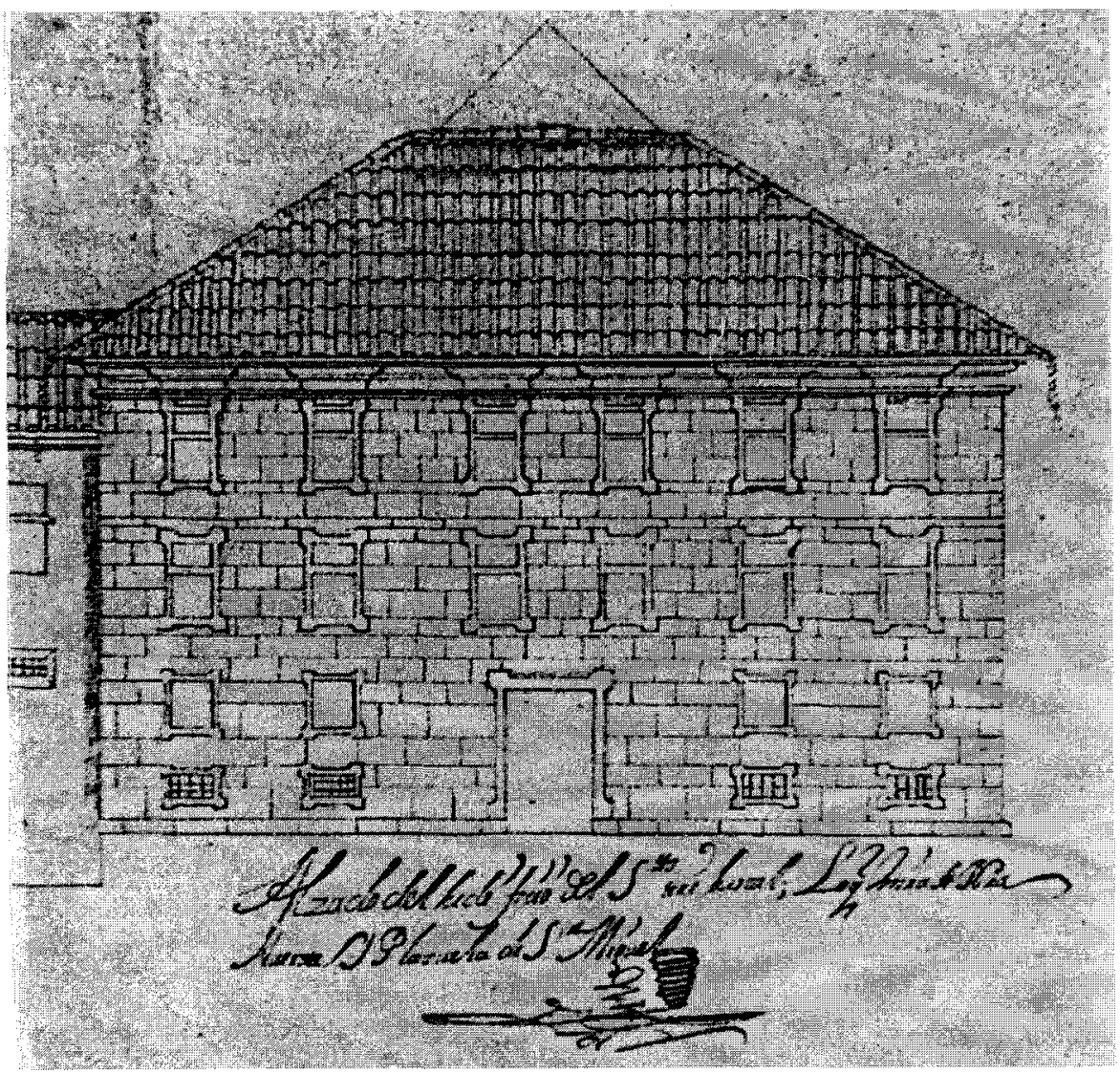

Fig. 9. Alzado del Palacio del Santo Tribunal dibujado por Fernando de Casas.

vesada de Norte a Sur por la traída de aguas a Santiago desde los vecinos montes de Vite ${ }^{18}$. En el plano, la traída desemboca en una gran arqueta que provee del líquido elemento no sólo a la fuente pública sino también al Santo Tribunal, a San Martín y al cercano convento de San Francisco ${ }^{19}$, para después seguir su camino: de una arqueta menor parte el caño que, creo, se dirige a la nueva fuente del monasterio be-

${ }_{13}$ Sobre la traida véanse los informes redactados por Domingo de Andrade en 1673 y 1674 Cfr. Taín Guzmán, M., Domingo de Andrade, Tesis Doctoral inédita, 1997, vol. II, 429-433.

${ }_{19}$ Cfr. CASTRO, M. DE, «Tres pleitos de aguas en Santiago durante los siglos XVII y XVIII», Cuadernos de Estudios Gallegos, 1969, 413-462. 


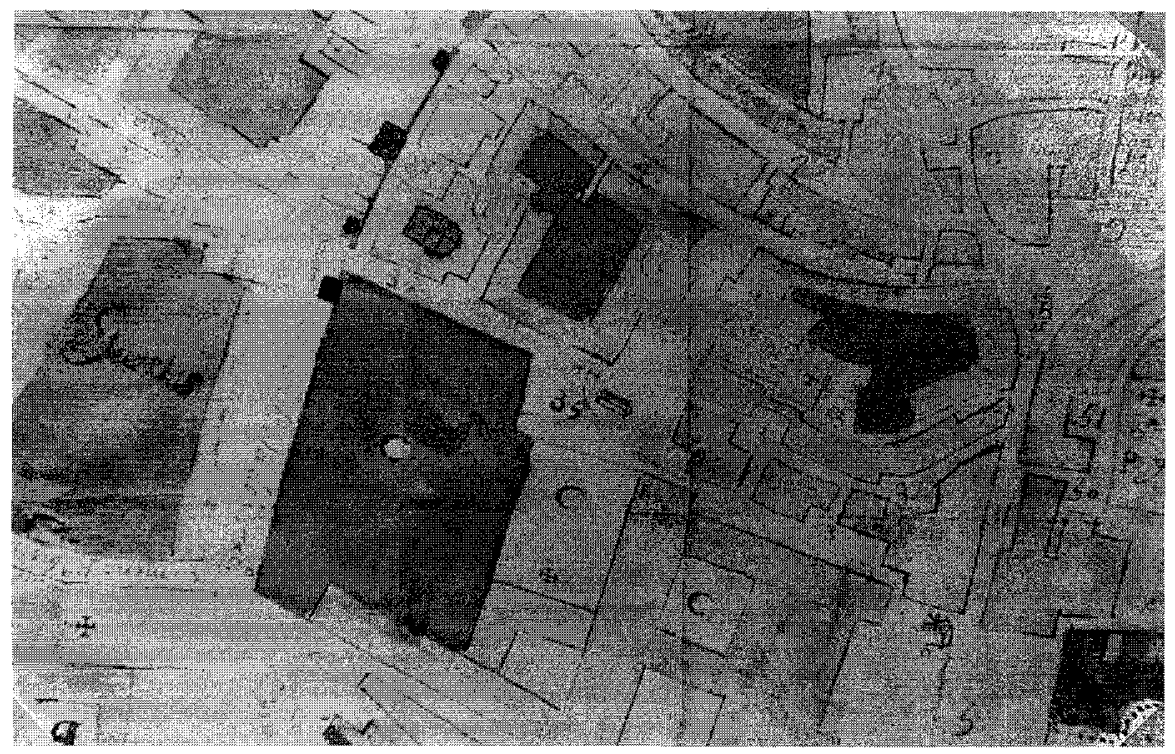

Fig. 10. Detalle de un plano de la ciudad de Santiago de hacia 1750. Las plazuelas de San Martín y de San Miguel.

nedictino ${ }^{20}$; de otra parten tres canales, uno hacia el monasterio de San Paio, otro hacia el colegio de San Jerónimo y un tercero hacia la fuente de San Juan. La traída llegaba hasta el Palacio Arzobispal y la fuente de la Plaza de las Platerías, propiedad del Cabildo de la Catedral ${ }^{21}$, dirigiéndose también a otras partes de la ciudad ${ }^{22}$. A cada fuente y organismo llegaba una cantidad diferente de agua según el diámetro de la tubería concedido. Todas las arquetas contaban con su cerradura para evitar abusos y la contaminación de las aguas. Una llave se la quedaba el ayuntamiento y otra la institución interesada. Cada cierto tiempo se inspeccionaba el depósito y se le limpiaba de barro y otras impurezas. Toda la red descrita no sólo dependía del Ayuntamiento, sino que sobre ella también ostentaban derechos el Cabildo de la Catedral y el arzobispo de turno como Señor de la Ciudad, costeando las tres instituciones cualquier obra de envergadura ${ }^{23}$.

20 Sobre el tema véase Fernández REY, A.A., op. cit., 374-375.

21 Cfr. TAín GuZmán, M., op. cit., vol.I, 479-484

22 Sólo tres fuentes de la ciudad se proveen de manantiales propios situados in situ. Se trata de las fuentes de San Pedro, de Sequelo y de la Rúa del Franco. Cfr. Hoyo, J. DEL, op. cit., 43.

${ }_{23}$ Sobre el tema en general véase CASTRO, M. DE, art. cit., 413-462. 
La Fuente de San Miguel del dibujo es muy sencilla. Consta de una pila circular resguardada por un parapeto al que antecede un peldaño. Pegado a ella se dispone un gran pilón cuadrangular, probable abrevadero. En el plano de 1750 la fuente parece conservarse con leves cambios (fig. 10). La actual es de diseño moderno.

\section{LA PLAZUELA DE SAN MIGUEL}

Transversalmente a la Plaza de San Martín se dispone la Plazuela de San Miguel, espacio de traza rectangular y en pendiente pronunciada que apenas ha cambiado a lo largo de los siglos (figs. 4, 8, 10 y 11-13). Su génesis está en relación con la iglesia parroquial de San Miguel dos Agros, cuya planta figura en el plano. Ésta no es la del templo actual sino de la del anterior, medieval ${ }^{24}$, uno de los más antiguos de la ciudad y centro de

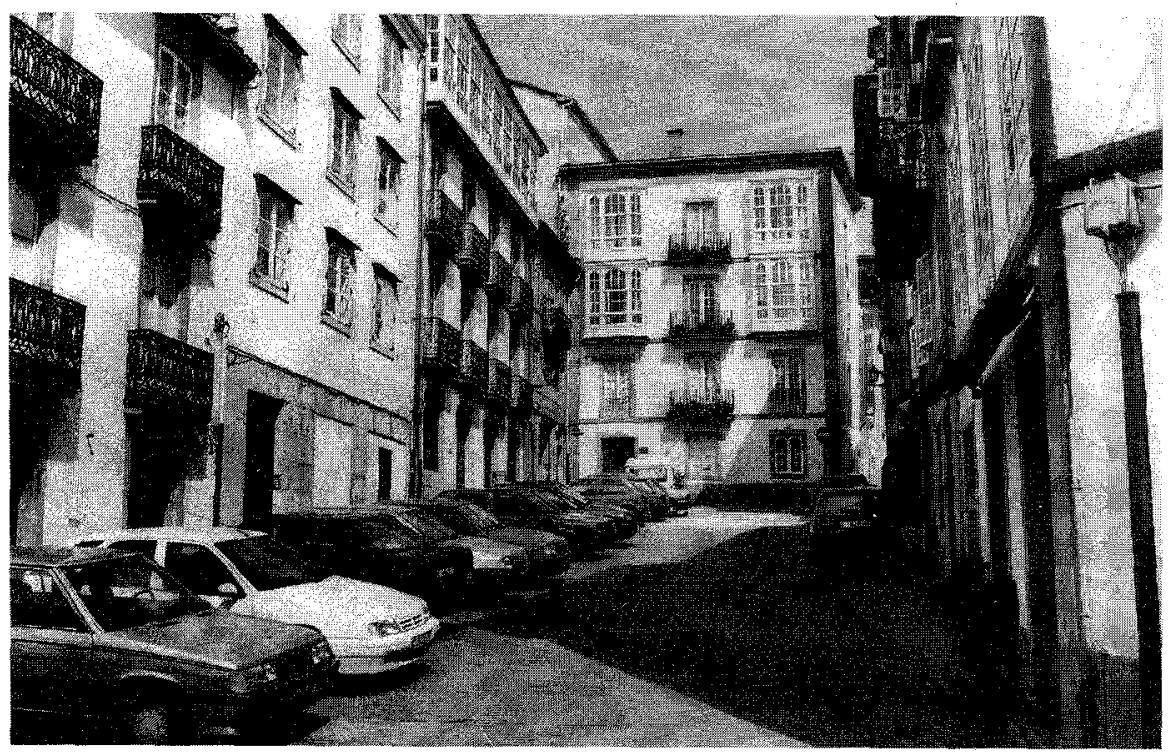

Fig. 11. La Plazuela de San Miguel hoy.

24 Una primera iglesia ya existía en 1110. En tiempos del arzobispo Gelmírez se construyó la románica que figura en el plano. Según Yzquierdo Perrín, de la fábrica gelmiriana hoy sólo queda parte de los muros laterales, restos de la puerta Sur, algunos sillares reaprovechados y el Agnus Dei que corona el frontón de la fachada. Cfr. YzQuierdo Perrín, R., "San Miguel dos Agros», Santiago de Compostela, A Cocuña, 1993, 160-167. 


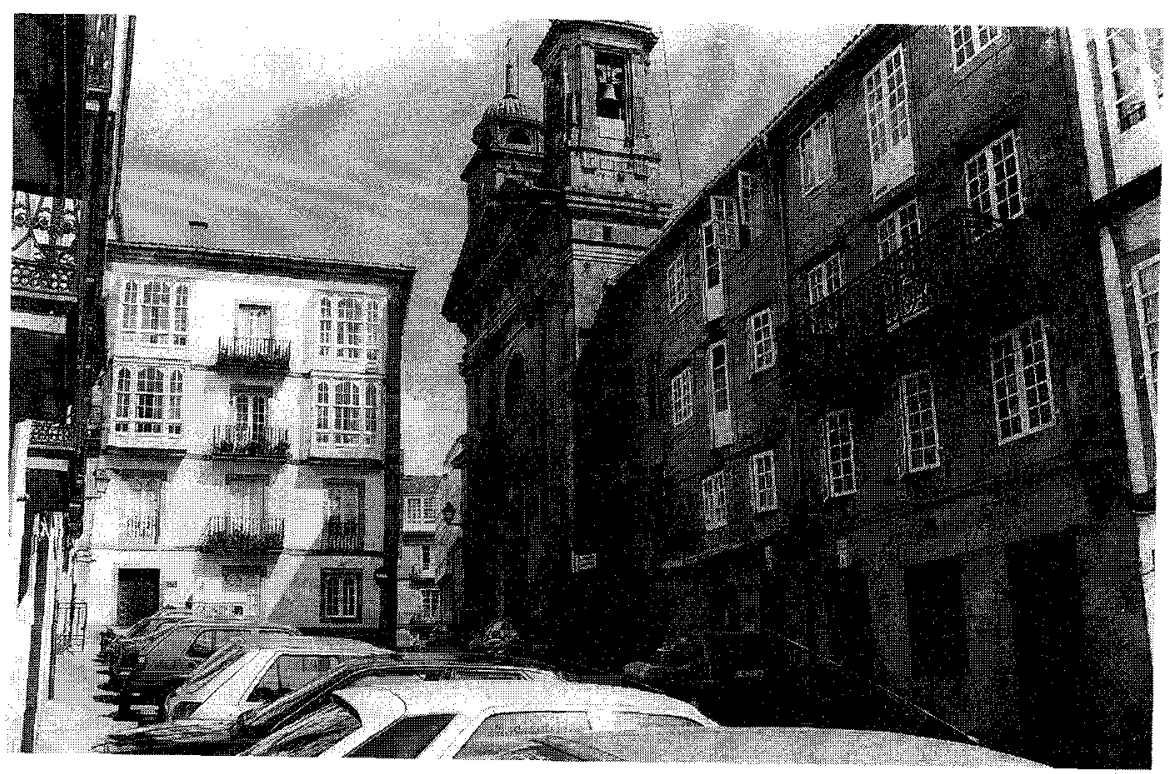

Fig. 12. La Plazuela de San Miguel

uno de los barrios con más solera. Su orientación tampoco coincide con la de hoy día de Norte a Sur. Los cambios en el edificio comenzaron en 1745 cuando Sarela, siguiendo planos de Fernando de Casas, contrata la construcción de las bóvedas de la iglesia, y llegan hasta 1823 en que José Otero, siguiendo su propia traza, construye la nueva fachada neoclásica hacia la plaza colindante ${ }^{25}$. Martí Arís afirma que esta última reforma del edificio provocó la transformación en el sistema de acceso que hasta entonces se hacia por el Oeste ${ }^{26}$. Sin embargo, el hecho de que la calle que limita con la iglesia por esa vertiente se llame en el plano Calleja de Tras San Migue/ me lleva a pensar que la entrada fue siempre lateral y desde la Plaza de San Miguel: las actuales calles compostelanas de Tras del Pilar y Tras Salomé se encuentran detrás de las cabeceras de las iglesias cuyo nombre ostentan.

La ubicación de la antigua iglesia explica los nombres de Calle de San Miguel, que desemboca en la plaza por el Este, y de la Ruela de

25 Cfr. Couselo Bouzas, J., Galicia artística en el siglo XVIII y primer tercio del XIX, Compostela, 1932, 310 y $485-486$. 1995,48 .

26 Cfr. MARTI ARIS, C., Santiago de Compostela: la ciudad histórica como presente, Santiago, 


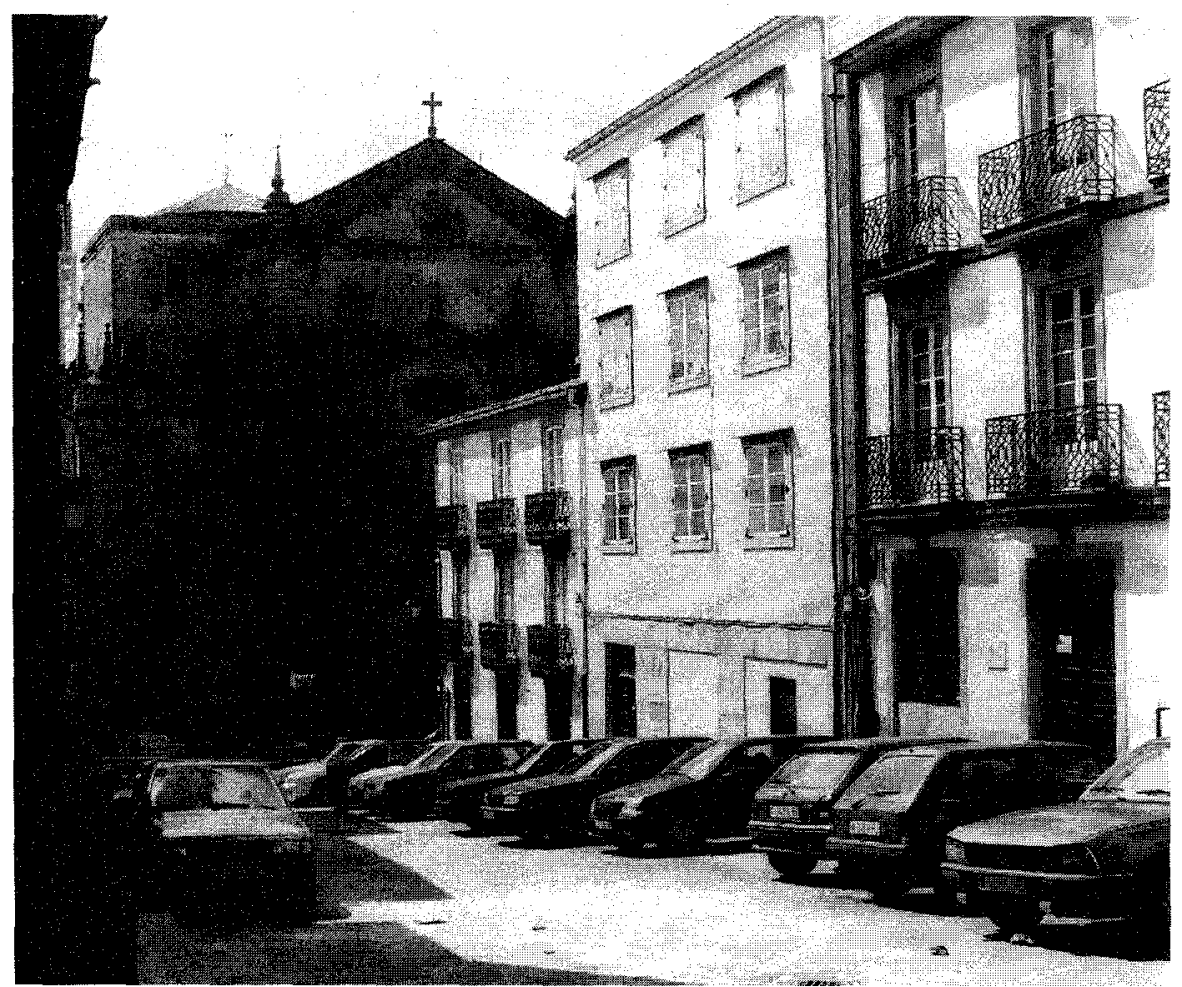

Fig. 13. La Plazuela de San Miguel hoy.

Xerusalén que, como ya he indicado, en el plano se llama Calleja de Tras San Miguel, aunque en otros documentos más antiguos ya se la designe con su nombre actual ${ }^{27}$. En el plano también figura parte de la casa gótica que hoy es sede del Museo de las Peregrinaciones. A principios del siglo XVIII vivía en ella un tal Francisco de Lamas.

En suma, el plano descubierto constituye uno de los pocos testimonios gráficos que se tienen de la ciudad de Santiago en esta época. Su detallismo permite analizar como eran las plazuelas de San Martín y de San Miguel a comienzos del siglo XVIII. Sorprendentemente no he encontrado ningún testimonio documental sobre el tipo de actividades que allí se desarrollaban. Ambas plazas eran punto de partida y de llegada de procesiones religiosas, pero no tengo constancia de que se celebrasen en ellas

${ }^{27}$ Así sucede en el manuscrito de JeRónimo DEL Horo (op. cit., 135-136). 
otros actos públicos, ni siquiera actividades mercantiles. Posiblemente desde la instalación en la Plazuela de San Martín del Tribunal de la Inquisición dicho espacio tuviese algo que ver con las actividades de este organismo ${ }^{28}$. En todo caso las dos plazas eran espacios de convivencia vecinal, sobre todo la de San Martín, con su fuente a la que acudían las mujeres a buscar el agua con las típicas "sellas» ${ }^{29}$.

28 Sobre las actividades del Tribunal en la ciudad véase CONTRERAS, J., op. cit.

${ }^{29}$ Al respecto son muy ilustrativas las viejas fotografías de las colas y coros de mujeres que se formaban para recoger el agua en otras fuentes de la ciudad. 
